\title{
Knowledge and attitude of Uyghur women in Xinjiang province of China related to the prevention and early detection of cervical cancer
}

\author{
Abida Abudukadeer, Sumeyya Azam ${ }^{\dagger}$, Ayi Zuoremu Mutailipu ${ }^{\dagger}$, Liu Qun, Guo Guilin and Sayipujiamali Mijiti
}

\begin{abstract}
Background: Cervical cancer is one of the commonest causes of cancer-related deaths worldwide. The prevalence rate of cervical cancer in Uyghur women in Xinjiang Autonomous Region of China has been remarkably higher than the ethnic groups living in the same region. This study aimed to assess the knowledge level and attitude of cervical cancer and its issues among the Uyghur women in Xinjiang province of China.

Methods: A cross-sectional interview-based survey of 5,000 Uyghur women was developed from 2013 to 2014 in Xinjiang autonomous region, to assess their knowledge and perception of cervical cancer and its issues. The collection of data was based on the questionnaire items.

Results: According to the questionnaire items, we collected a data for 5,000 participants. A very small proportion of participants had heard of the cervical cancer, human papillomavirus (HPV), and HPV vaccine, that is, 27.0\%, 13.0\% and, $6.0 \%$, respectively. According to the demographic characteristics, women aged 31 to 40 years were more aware of the knowledge of cervical cancer (32.9\%), HPV (17.8\%), and HPV vaccine (9.1\%), and women with undergraduate or higher educational level had more knowledge of cervical cancer (30.0\%), HPV (21.0\%), and HPV vaccine (9.7\%).

Conclusions: From our study, we concluded that Uyghur women need more information about cervical cancer and its risk factors. Lack of the related knowledge about cervical cancer may be one of the important factors for high incidence rate of cervical cancer in Uyghur population. In order to reduce the incidence rate and mortality of cervical cancer in Uyghur women and to make extensive health education to raise awareness of cervical cancer and HPV is strongly needed than prophylactic vaccination.
\end{abstract}

Keywords: Cervical cancer, Human papillomavirus, Human papillomavirus vaccine

\section{Background}

Cervical cancer continues to be one of the leading female genital cancers worldwide. About $80 \%$ of cases occur in developing countries and about $87 \%$ cervical cancer deaths occur in less developed regions [1-3]. China accounts for $29.0 \%$ of the $51,000,000$ new cases of cervical cancer each year [4]. In China, there is an annual incidence of about 46,000 cases, and cervical cancer presents a major health problem [5].

Xinjiang province has the highest incidence (590/ 100,000) and mortality rate of cervical cancer in China,

\footnotetext{
*Correspondence: abida0724@126.com

${ }^{\dagger}$ Equal contributors

Department of Gynaecology, First Affiliated Hospital of Xinjiang Medical University, 830054, No. 393 Xin Yi road, Urumqi, Xinjiang, People's Republic
} of China

\section{Biomed Central}

especially the south of Xinjiang. The incidence of cervical cancer among the Uyghur women is four times higher than the mean incidence of China $(138 / 100,000)$ [6,7]. The prevalence of cervical cancer in Uyghur women has been remarkably higher than the ethnic groups living in the same region, and the mortality rate was more than the other ethnic minorities in China.

Epidemiologic evidence clearly indicates that high-risk human papillomavirus (HPV) is the principal cause of invasive cervical cancer and cervical intraepithelial neoplasia (CIN). Invasive cervical cancer is attributed to HPV infection. Seventy percent of the cancers are known to be caused by HPV 16 or 18 [8].

According to our previous study, HPV 16 was the most common type detected in Uyghur women with squamous 
cell carcinoma and CIN in Xinjiang. The prevalence of HPV 18 and 58 was relatively low, and all other types were absent. Together with the high infection rate, this may be the reason for the fourfold higher cervical cancer incidence in this province and in this population [9].

Cervical cancer is a deadly disease once it reaches the invasive stages, but out of all the female genital tract cancers, it is the only preventable cancer if detected at its early stages [10]. Therefore, the key to reducing cancer morbidity and mortality is still the early detection and treatment of pre-cancerous lesions.

Cervical cancer can be effectively controlled through primary and secondary prevention such as, cervical screening and prophylactic HPV vaccination. Since the Pap smear test was introduced for routine screening, a substantial decline has been witnessed in cervical cancer deaths in developed countries in the last four decades [11].

It is a general consensus that the cytology screening for cervical cancer is effective in reducing the incidence and mortality in developed countries. In contrast to this striking result, cervical cancer is the second most common cancer among women and the leading cause of cancer death in developing countries due to inadequate use of the screening service.

HPV vaccines are expected to effectively avert cervical morbidity and mortality in China, if it was routinely used in women. But because of the limitations of prophylactic HPV vaccination, it is imposing a substantial burden to the women health in the developing countries. Therefore, evaluate the awareness and knowledge of screening for cervical cancer among the high risk people and to make good education program is vital to reduce the incidence of cervical cancer in developing countries. Various studies have been undertaken to evaluate women's awareness and knowledge of cervical cancer and screening for cervical cancer [12-14].

With the lack of knowledge about the disease and familiarity with the concept of prevention, there is no way to mention early detection of cervical cancer and use of HPV vaccination.

It is not clear how well HPV and its association to cervical cancer is known in the general population, especially in Xinjiang.

This study was undertaken to explore the knowledge of Uyghur women in Xinjiang Autonomous Region, China, regarding cervical cancer issues, HPV, and HPV vaccine.

\section{Methods}

\section{Setting}

A cross-sectional study was carried out among the Uyghur women in Xinjiang province of China. A total of 5,000 women were recruited in our investigation between 2013 and 2014. The sample population was composed of $\leq 20$ years to $\geq 51$ year olds. A questionnaire with the options of 'yes' and 'no' for each item was used for the collection of data. A total of 5,625 questionnaires were distributed, and out of them, 5,000 participants responded. The participants were recruited after door-todoor investigation. Face-to-face interviews were administered by the team of doctors from the First Affiliated Hospital of Xinjiang Medical University, China.

\section{Questionnaire/data collection}

The underlying concept and format of the questionnaire was developed by our review of literature and research hypotheses. The questionnaire was designed to assess the knowledge about cervical cancer, HPV, and HPV vaccine by demographic variables and life style factors. The questionnaire was modeled in such a manner that the women could provide answers to the personal questions in private, without requiring assistance of an interviewer.

The listed questionnaire items were also mentioned in Uyghur language to avoid language barrier and to get better response from the respondents.

Prior to the initiation of the survey, practice interviews were conducted in order to ensure that the interviews were undertaken in a standardized manner. The study design was approved by the Ethics Committee of First Affiliated Hospital of Xinjiang Medical University.

\section{Data analysis}

For statistical analysis, SPSS statistics (version 17.0) was used. Chi-squared $\left(X^{2}\right)$ test was used to examine the differences in demographic variables between women with knowledge about cervical cancer, HPV, and HPV vaccine. Logistic regression was used with the inclusion of age and education as the factors in the logistic regression models. $P$ value of $<0.05$ was considered statistically significant.

\section{Results}

A total of 5,625 questionnaires were distributed, and out of them, 5,000 (88.9\%) participants responded. The age of the women ranged from $\leq 20$ years to $\geq 51$ year olds.

Table 1 comprises the questionnaire items showing the Uyghur women knowledge about cervical cancer and issues related to it.

The women were asked to tell whether or not they had heard of cervical cancer and then asked to provide answers of 13 more questions that served to evaluate the level of cervical cancer and HPV knowledge.

\section{Cervical cancer knowledge}

Overall, very less proportion of participants (1,350 (27.0\%)) had heard of cervical cancer. Out of them, 475 (35.2\%) responded that they heard of cervical cancer from friends, 
Table 1 Uyghur women knowledge and analysis of related elements of cervical cancer, HPV, and HPV vaccine

\begin{tabular}{lll}
\hline Questionnaire items & \multicolumn{2}{l}{ Uyghur women } \\
\cline { 2 - 3 } & Number & Percentag \\
\hline Have you heard of cervical cancer? & 1,350 & 27 \\
Yes & 3,650 & 73 \\
No & & \\
From where you heard of cervical cancer? & 475 & 35.2 \\
Friends & 458 & 33.9 \\
Television & 117 & 8.7 \\
Broadcast & 90 & 6.7 \\
Magazine & 210 & 15.5 \\
Others & 3,650 & 73.0 \\
Do not know &
\end{tabular}

Do you know the need of cervical cancer screening once a year?

$\begin{array}{lll}\text { Yes } & 1,000 & 20.0 \\ \text { No } & 4,000 & 80.0\end{array}$

Do you know the risk factors of cervical cancer? Yes

HPV

Having HIV

$900 \quad 18.0$

Smoking

Using birth control pills for a long time (5 or more years)

Having given birth to three or more 64 children

Having several sexual partners $\quad 104 \quad 2.08$

Being younger than 17 at first full term $\quad 79 \quad 1.58$ pregnancy

Having a family history of cervical cancer $\quad 112 \quad 2.24$

No

4,100

Do you want to have regular gynaecological examination?

$\begin{array}{lll}\text { Yes } & 900 \quad 18.0\end{array}$

No $\quad 4,100 \quad 82.0$

Why you never had regular gynaecological examination?

Because of the economy problem $\quad 1,681 \quad 41.0$

Because of lack of awareness of the $\quad 1,804 \quad 44.0$

importance of regular gynaecological

examination

Because of lack of time $\quad 1,515 \quad 30.3$

Have you ever had cervical Pap smear test?

$\begin{array}{lll}\text { Yes } & 1,650 \quad 33.0\end{array}$

No $\quad 3,350 \quad 67.0$

Do you know the significance of cervical Pap smear test?

$\begin{array}{lll}\text { Yes } & 1,350 \quad 27.0\end{array}$

$\begin{array}{lll}\text { No } & 3,650 \quad 73.0\end{array}$
Table 1 Uyghur women knowledge and analysis of related elements of cervical cancer, HPV, and HPV vaccine (Continued)

\begin{tabular}{|c|c|c|}
\hline \multicolumn{3}{|c|}{ Have you heard of HPV? } \\
\hline Yes & 650 & 13.0 \\
\hline No & 4,350 & 87.0 \\
\hline \multicolumn{3}{|c|}{ Do you know the link between HPV and cervical cancer? } \\
\hline Yes & 350 & 7.0 \\
\hline No & 4,650 & 93.0 \\
\hline \multicolumn{3}{|c|}{ Have you ever had an HPV test before? } \\
\hline Yes & 450 & 9.0 \\
\hline No & 4,550 & 91.0 \\
\hline \multicolumn{3}{|c|}{ Have you heard of HPV vaccine? } \\
\hline Yes & 300 & 6.0 \\
\hline No & 4,700 & 94.0 \\
\hline \multicolumn{3}{|c|}{ Do you think men could be the risk factor for cervical cancer? } \\
\hline Yes & 1,250 & 25.0 \\
\hline No & 3,750 & 75.0 \\
\hline \multicolumn{3}{|c|}{$\begin{array}{l}\text { Do you think sexually transmitted diseases can be prevented if men } \\
\text { use condoms? }\end{array}$} \\
\hline Yes & 1,400 & 28.0 \\
\hline No & 3,600 & 72.0 \\
\hline
\end{tabular}

458 (33.9\%) responded that they heard of cervical cancer through television, 117 (8.7\%) responded they had heard of cervical cancer from broadcast, 90 (6.7\%) responded that they got to know about cervical cancer from magazines, $210(15.5 \%)$ of the respondents had heard of it by other means, whereas 3,650 (73.0\%) participants were unsure about it. A total of 3,650 (73.0\%) participants had never heard of cervical cancer. As shown in Table 2, at least $1,385(27.7 \%)$ participants had undergraduate or higher level of education. Women who had undergraduate or higher level of education had more awareness of cervical cancer, that is, $30.0 \%$ as compared to the women with lower level of education. So, a significant difference was found in the educational levels of the participants with different levels of knowledge about cervical cancer $(P<0.05)$.

As shown in Table 3, most of the participants were between the ages of 31 and 40 years. A total of 1665 (33.3\%) participants were ranged between the age group of 31-40 years. Out of them 549 (32.9\%) participants were aware of cervical cancer. Participants aged $\leq 20$ years were less that is, $330(6.6 \%)$ participants. And out of them only $65(19.7 \%)$ participants knew about cervical cancer. The difference was statistically significant $(\mathrm{P}<0.05)$.

According to the analysis of related elements of cervical cancer, shown in Table 1, the overall knowledge of the risk factors for cervical cancer was generally poor with only $900(18.0 \%)$ women knowing at least one of 
Table 2 Assessment of Uyghur women knowledge by educational level

\begin{tabular}{|c|c|c|c|c|c|c|c|c|}
\hline & \multicolumn{2}{|c|}{ Participants } & \multicolumn{2}{|c|}{ Aware of cervical cancer } & \multicolumn{2}{|c|}{ Aware of HPV } & \multicolumn{2}{|c|}{ Aware of HPV vaccine } \\
\hline & Number & Percentage & Number & Percentage & Number & Percentage & Number & Percentage \\
\hline Illiteracy & 315 & 6.3 & 53 & 16.8 & 12 & 3.8 & 7 & 2.2 \\
\hline Primary education & 1,000 & 20.0 & 247 & 24.9 & 71 & 7.1 & 35 & 3.6 \\
\hline Secondary education & 1,085 & 21.7 & 285 & 26.3 & 102 & 9.4 & 49 & 4.5 \\
\hline Specialist/professional education & 1,215 & 24.3 & 349 & 28.7 & 173 & 14.3 & 74 & 6.1 \\
\hline Undergraduate or higher education & 1,385 & 27.7 & 416 & 30.0 & 292 & 21.0 & 135 & 9.7 \\
\hline$P$ value & & & $P=0.000$ & & $P=0.000$ & & $P=0.000$ & \\
\hline
\end{tabular}

Linear-by-linear association has been used; the difference was statistically significant $P<0.05$. With the increase of educational level, awareness has increased.

the risk factors. Out of them, $82(1.64 \%)$ women answered affirmatively that HIV could be one of the risk factors of cervical cancer, 67 (1.34\%) participants answered affirmatively for smoking as a risk factor, 42 $(0.84 \%)$ participants knew that using birth control pills for a long time could be a risk factor for cervical cancer, $64(1.28 \%)$ participants answered 'yes' for having given birth to three or more children and, 79 (1.58\%) participants answered 'yes' for being younger than 17 at first term pregnancy as a risk factor for cervical cancer. Most of the participants answered affirmatively for HPV, having several sexual partners and, having a family history of cervical cancer, that is, $350(7.0 \%)$ participants, 104 (2.08\%) participants, and 112 (2.24\%) participants, respectively, whereas majority of the study population $(4,100(82.0 \%))$ were unaware of the risk factors of cervical cancer, and only 1,250 (25.0\%) participants had an idea that males could be the risk factor for cervical cancer. Next, we asked some general questions regarding all the possible reasons for women that 'Do you want to have regular gynaecological examination?' Only 900 (18.0\%) participants answered affirmatively, whereas 4,100 (82.0\%) participants refused to have regular gynaecological examination. Furthermore, we asked 'why they never had regular gynaecological examination?' Of the participants, 1,804 (44.0\%) answered that they were unaware of the importance of regular gynaecological examination, 1,681 (41.0\%) participants answered that they had financial problems, and 1,515 (30.3\%) participants answered that they were having lack of time. Of the study population, 1,650
(33.0\%) had and 3,350 (67.0\%) had not previously undergone Pap smear tests, and 1,350 (27.0\%) women knew the significance of cervical Pap smear tests, whereas 3,650 (73.0\%) women were unaware of the significance of cervical Pap smear tests. Among the respondents, only 1,000 (20.0\%) women had the awareness of the need of cervical cancer screening once a year, whereas 4,000 (80.0\%) women had no awareness of its need.

\section{HPV knowledge}

Overall, only $650(13.0 \%)$ of the participants answered that they had awareness of HPV and out of them 292 (21.0\%) participants had undergraduate or higher educational level (Table 2). A large number of the participants, that is, $4,350(87.0 \%)$ participants were totally unaware of HPV. A statistically significant difference was found among the educational levels of the participants with different levels of knowledge of HPV $(P<0.05)$.

As shown in Table 3, according to the different age group women knowledge about HPV, overall 650 (13.0\%) women knew about HPV. Most of the participants were between the age of 31 and 40 years. Out of the 1,665 (33.3\%) participants between the age group of 31 to 40 years, 297 (17.8\%) participants knew about HPV. A statistically significant difference $(P<0.05)$ was identified in age groups relative to the women with different knowledge levels of HPV. Furthermore, only 350 (7.0\%) participants knew the link between HPV and cervical cancer, whereas 4,650 (93.0\%) participants had no idea about it. Four hundred fifty (9.0\%) participants had and 4,550

Table 3 Assessment of Uyghur women knowledge according to the age group

\begin{tabular}{|c|c|c|c|c|c|c|c|c|}
\hline \multirow[t]{2}{*}{ Group } & \multicolumn{2}{|c|}{ Participants } & \multicolumn{2}{|c|}{ Aware of cervical cancer } & \multicolumn{2}{|c|}{ Aware of HPV } & \multicolumn{2}{|c|}{ Aware of HPV vaccine } \\
\hline & Number & Percentage & Number & Percentage & Number & Percentage & Number & Percentage \\
\hline$\leq 20$ years & 330 & 6.6 & 65 & 19.7 & 11 & 3.3 & 8 & 2.4 \\
\hline 21 to 30 years & 1,330 & 26.6 & 317 & 23.8 & 123 & 9.2 & 72 & 5.4 \\
\hline 31 to 40 years & 1,665 & 33.3 & 549 & 32.9 & 297 & 17.8 & 152 & 9.1 \\
\hline 41 to 50 years & 1,165 & 23.3 & 302 & 25.9 & 170 & 14.6 & 46 & 3.9 \\
\hline$\geq 51$ years & 510 & 10.2 & 117 & 22.9 & 49 & 9.6 & 22 & 4.3 \\
\hline$P$ value & & & $P=0.000$ & & $P=0.000$ & & $P=0.000$ & \\
\hline
\end{tabular}

Chi-squared $\left(X^{2}\right)$ test has been used; the difference was statistically significant when $P<0.05$. 
(91.0\%) participant had not previously undergone HPV test.

\section{Knowledge of HPV vaccine}

Overall, only 300 (6.0\%) participants had heard of HPV vaccine, whereas 4,700 (90.0\%) had never heard of HPV vaccine (Table 1 ).

According to Table 2, 1,385(27.7\%) participants had undergraduate or higher levels of education, which was more than the women who had lower educational level. Only 290 (6.0\%) participants had an affirmative answer about their knowledge of HPV vaccine. Participants with undergraduate or higher level of education had more awareness of HPV vaccine, that is, 135 (9.7\%). A statistically significant difference was identified among the different educational levels of the women with different knowledge levels about HPV vaccine.

As previously mentioned that most of the participants were between the age of 31 and 40 years (Table 3), 152 (9.1\%) participants between this age group had more knowledge of HPV vaccine. The difference was statistically significant $(P<0.05)$.

\section{Discussion}

To our knowledge, this is the largest study that has indicated the awareness of cervical cancer screening and HPV among Uyghur women in Xinjiang, a high-incidence region of cervical cancer in China. Lack of knowledge about cervical cancer and Pap smear, certain demographic factors and unfavourable attitude towards Pap smear test can have negative impact on utilization of the test by women. On the other hand, cervical cancer preventive programs can be effective in increasing cervical cancer knowledge, perceived susceptibility, and cancer prevention behaviour [15].

A cross-sectional study was carried out among the 5,000 Uyghur women in Xinjiang Uyghur Autonomous region, China. The purpose was to evaluate their knowledge regarding cervical cancer, HPV and HPV vaccine. The resultant of this survey was that less than a quarter of the respondents were not at all or very less aware of cervical cancer, HPV, and HPV vaccine.

As foreseeable, awareness was lower in women with lower educational levels. With the increase of educational level, awareness has increased. Earlier studies have shown important association between health behaviour and educational level [16]. Low literacy is associated with low income and poor health status. Cervical cancer mortality rate is markedly higher among illiterate women. Interventions aimed at improving health literacy may result in more functional interaction with the healthcare system and less anxiety related to illness, and it may affect the health patterns of a woman's family members [17].
Developed countries are far ahead because of both organized and opportunistic Pap screening programs. Screening rate and Pap smear coverage are $88 \%$ and $93 \%$, respectively, in the USA $[18,19]$. Cervical cancer screening rate is $63.9 \%$ in South Korea, while $7 \%$ in rural India [20], 9.8\% in South Africa [21], 17.2\% in Sri Lanka [22], 27.1\% in Iran [23], and 45.2\% in South Turkey [24].

Since the Papanicolaou (Pap) smear test was introduced for routine screening, a substantial decline has been witnessed in cervical cancer deaths in developed countries in the last four decades [25].

A recent survey in Nepal found that only $15.7 \%$ of the participants had utilized cervical Pap smear test in the past [26] which is lower than that reported in our survey. In the current study, $33.0 \%$ of the participants responded that they had utilized cervical Pap smear test in the past and the knowledge about the need of cancer screening once a year was present only in $20.0 \%$ of the respondents. Women's attitude and practices towards screening were negative. Our survey suggests a strong need to raise public awareness about cervical cancer screening.

Because of the limitations of prophylactic vaccination especially in developing countries, cervical screening test is still a very effective and useful method for reducing high incidence and mortality of cervical cancer in Xinjiang.

In developed countries, cervical screening programs have reduced the incidence of invasive cervical cancer up to $80.0 \%$ although this decline has now reached a plateau with current cancers occurring in patients who have failed to attend for screening or where the sensitivity of the tests have proven inadequate.

It is known that precancerous lesions are detectable for a few years or more before cancer develops. If our people have related knowledge and health conception about cervical cancer screening, then this is a long enough golden period and good opportunity to screen and prevent this disease.

In order to control or reduce high incidence of cervical cancer, elevation of knowledge level about cervical cancer is more important than prophylactic vaccination in Xinjiang. It was an important task and project on the prevention and to control the incidence of cervical cancer.

The comparison of the findings of the current study with the other recent surveys is shown in Table 4.

Table 4 clearly shows that the rates reported in our survey are remarkably lower than the previous surveys. Low levels of knowledge were also reported in a survey [27] that only $19.0 \%$ of adult Korean women knew that HPV infection was a risk factor for cervical cancer. Yet, in another study among Chinese women [28], it was found that only $26.9 \%$ of the respondents knew that HPV infections were risk factors for cervical cancer. The findings of all these studies showed that women lacked 
Table 4 Comparison of the current study results with the other recent surveys regarding cervical cancer knowledge

\begin{tabular}{lccc}
\hline & Basu P [32] & Pan XF [33] & $\begin{array}{c}\text { Montgomery MP [34] } \\
\text { Current } \\
\text { study }\end{array}$ \\
\hline Aware of cervical cancer & $38.0 \%$ & $15.0 \%$ & $36.0 \%$ \\
Aware of HPV & & $77.9 \%$ & $27.0 \%$ \\
Aware of HPV vaccine & $5.5 \%$ & $29.0 \%$ & $26.0 \%$ \\
Aware of the link between HPV and cervical cancer & & $28.0 \%$ & $7.0 \%$ \\
Aware of Pap smear test & $18.4 \%$ & $33.6 \%$ & $3.0 \%$ \\
Had Pap smear test in the past & $12.6 \%$ & $33.0 \%$ \\
Aware of multiple pregnancies as a risk factor for cervical cancer & $25.8 \%$ & $33.0 \%$ & \\
Aware of multiple sex partners as a risk factor for cervical cancer & $60.0 \%$ \\
Aware of the prevention of sexually transmitted diseases prevention by condoms. & $2.08 \%$ \\
\hline
\end{tabular}

adequate knowledge of cervical cancer and risk factors. In comparison to all these studies, the current study showed relatively low levels of awareness among Uyghur women.

Similar low levels of knowledge regarding cervical cancer in the general population have also been seen in other Asian countries where there are no cervical cancer screening programs [29].

A recent survey conducted in Mangalore, India, reported that women who were between the age group of 35 to 40 years had more knowledge of cervical cancer and issues related to it [30]. This is similar to our survey that reported that the women between the age group of 31 to 40 years had more awareness of cervical cancer.

The knowledge improved significantly with improvement in the level of education. Several research studies have shown that health education through different teaching strategies is an effective way of imparting knowledge. Education is needed to prevent the incidence of cervical cancer [31,32]. The education programs are very effective in increasing cervical cancer knowledge, perceived susceptibility, and cancer prevention behaviours [15]. By education, women can be empowered with knowledge of cervical cancer, its early warning symptoms and the availability of adequate therapies [30].

A recent study conducted in Maldives reported that the exposure of the women of Maldives to the risk factors of cervical cancer is high, and the awareness about cervical cancer, its risk factors, and the methods of prevention is very limited [29]. Our survey reported the same results that despite of relatively higher incidence rate of cervical cancer in Xinjiang, less than a quarter of the respondents were not at all or very less aware of cervical cancer, HPV, and HPV vaccine.

We investigated a lowest level of knowledge or awareness, that is, having heard of HPV, lack of knowledge about cervical cancer, HPV infection, and its possible consequences are great impediment for reducing incidence of cervical cancer in high incidence area, Xinjiang.
The current national policy of providing mandatory free education to all the Uyghur women is likely to have a major impact. Thus, health literacy programs which are effective not only in increasing knowledge but also in creating a positive attitude among women towards Pap smear test should be organized to increase Pap smear coverage in Xinjiang.

\section{Conclusions}

Overall, the study results indicated that Uyghur women's awareness or level of knowledge and attitude regarding cervical cancer, HPV, and HPV vaccine is way too low and unsatisfactory. In order to control or reduce high incidence of cervical cancer, elevation of knowledge level about cervical cancer is more important than prophylactic vaccination in Xinjiang. Healthcare services should take serious measures to educate women about cervical cancer, HPV, and the potential value of HPV vaccination. Our data highly suggested that educational programs are needed to prevent the incidence of cervical cancer among Uyghur women of Xinjiang, a high-incidence region of cervical cancer in China. Otherwise, it will continue to be a grave health problem in Xinjiang.

\section{Competing interests}

The authors declare that they have no competing interests.

\section{Authors' contributions}

Corresponding author (Abida Abudukadeer) designed this research paper, superwise and directed the authors on the content of the manuscript and paid the artical processing charges. First authors (Sumeyya Azam, Ayi Zuoremu Mutailipu) worked on collecting the data, statistical analysis, and writing of the manuscript. Other authors (Liu Qun, Guo Guilin, Sayipujiamali Mijiti) helped significantly on the collection of the data.

\section{Acknowledgements}

We are grateful to our team of authors and we also like to thank the participants in our study who generously donated their time to this study. The protocol for the research project has been approved by a suitably constituted Ethics Committee of the institution within which the work was undertaken. This work was funded by National Science Funding of China (NSFC 81360321). 
Received: 27 November 2014 Accepted: 28 February 2015

\section{Published online: 14 March 2015}

\section{References}

1. Franco EL, Schlecht NF, Saslow D. The epidemiology of cervical cancer. Cancer J. 2003;9(5):348-59.

2. GLOBOCON (2012). Estimated cancer incidence, mortality and prevalence worldwide in 2012. http://globocan.iarc.fr/Pages/fact_sheets_cancer.aspx.

3. Parkin DM. Global cancer statistics in the year 2000. Lancet Oncol. 2001;2(9):533-43.

4. Kim K, Zang R, Choi SC, Ryu SY, Kim JW. Current status of gynecological cancer in China. J Gynecol Oncol. 2009;20(2):72-6. doi:10.3802/jgo.2009. 20.2.72. Epub 2009 Jun 29.

5. Ferlay J, Parkin DM. GLOBOCAN 2002: cancer incidence, mortality and prevalence worldwide. IARC Cancer Base No. 5, version 2.0. IARC Press. 2004 http://www-dep.iarc.fr/.

6. Suzuke L, Peng Y, Zhou K. The analysis of pathogenetic tendency of cervical cancer in various ethnic groups in Xinjiang. Journal Xinjiang Medical University. 2006;29:569-71.

7. Guzalinuer A, Peng Z, Guo Y. HPV and its subtypes in the Han nationality in Sichuan and the northwestern region of Xinjiang Uyghur Southern region of cervical tissue of women differentially expressed. Chinese J Microbiol Immunology. 2004;24:402-6.

8. WHO (2013). Comprehensive cervical cancer prevention and control: a healthier future for girls and women. Available at http://www.who.int/ reproductivehealth/topics/cancers/en/.

9. Abudukadeer A, Ding Y, Niyazi M, Abudula A. Distribution of HPV genotypes in uterine cervical lesions among the Uighur women in Xinjiang province of China. Eur J Gynaecol Oncol. 2010;31(3):315-8.

10. Shah V, Vyas S, Singh A, Shrivastava M. Awareness and knowledge of cervical cancer and its prevention among the nursing staff of a tertiary health institute in Ahmedabad, Gujarat, India. Ecancermedicalscience. 2012;6:270. Epub 2012 Sep 25.

11. Dijkstra MG, Snijders PJ, Arbyn M, Rijkaart DC, Berkhof J, Meijer CJLM. Cervical cancer screening: on the way to a shift from cytology to full molecular screening. Ann Oncol. 2014. doi:10.1093/annonc/mdt538.

12. Sankaranarayanan R, Nene BM, Shastri SS, Jayant K, Muwonge R, Budukh AM, et al. HPV screening for cervical cancer in rural India. N Engl J Med. 2009:360:1385-94

13. Raychaudhuri S, Mandal S. Current status of knowledge, attitude and practice (kap) and screening for cervical cancer in countries at different levels of development. Asian Pac J Cancer Prev. 2012;13:4221-7.

14. Reis $\mathrm{N}$, Bebis $\mathrm{H}$, Kose $\mathrm{S}$, Sis A, Engin R, Yavan T. Knowledge, behavior and beliefs related to cervical cancer and screening among Turkish women. Asian Pac J Cancer Prev. 2012;13:1463-70.

15. Choi SY. Development of an educational program to prevent cervical cancer among immigrants in Korea. Asian Pac J Cancer Prev. 2013;14:5345-9.

16. Agurto I, Bishop A, Sánchez G, Betancourt Z, Robles S. Perceived barriers and benefits to cervical cancer screening in Latin America. Prev Med. 2004;39(1):91-8.

17. Lindau ST, Tomori C, Lyons T, Langseth L, Bennett CL, Garcia P. The association of health literacy with cervical cancer prevention knowledge and health behaviors in a multiethnic cohort of women. Am J Obstet Gynecol. 2002;186(5):938-43.

18. Sirovich B, Welch $\mathrm{G}$. The frequency of Pap smear screening in the United States. J Gen Intern Med. 2004;19:243-50.

19. Kim Y, Jun JK, Choi KS, Lee HY. Overview of the national cancer screening programme and the cancer screening status in Korea. Asian Pac J Cancer Prev. 2011;12:725-30

20. Shekhar S, Sharma C, Thakur S, Raina N. Cervical cancer screening: knowledge, attitude and practices among nursing staff in a tertiary level teaching institution of rural India. Asian Pac J Cancer Prev. 2013;14:3641-5.

21. Hoque E, Hoque M. Knowledge of and attitude towards cervical cancer among female university students in South Africa. South Afr J Epidemiol Infect. 2009;24(1):21-4.

22. Nilaweera RIW, Perera S, Paranagama N, Anushyanthan AS. Knowledge and practices on breast and cervical cancer screening methods among female health care workers: a Sri Lankan experience. Asian Pac J Cancer Prev. 2012:13:1193-6.

23. Chamani SR, Charandabi SM, Kamalifard M. Knowledge, attitudes and practice about pap smear among women referring to a public hospital. J Family and Reproductive Health. 2012;6(4):117-82.
24. Coskun S, Can H, Turan S. Knowledge about cervical cancer risk factors and Pap smear testing behavior among female primary health care workers: a study from South Turkey. Asian Pac J Cancer Prev. 2013;14:6389-92.

25. Dijkstra MG, Snijders PJ, Arbyn M, Rijkaart DC, Berkhof J, Meijer CJ. Cervical cancer screening: on the way to a shift from cytology to full molecular screening. Ann Oncol. 2014;25(5):927-35. doi:10.1093/annonc/mdt538. Epub 2014 Jan 19.

26. Ranabhat S, Tiwari M, Dhungana G, Shrestha R. Association of knowledge, attitude and demographic variables with cervical Pap smear practice in Nepal. Asian Pac J Cancer Prev. 2014;15(20):8905-10.

27. Oh JK, Lim MK, Yun EH, Lee EH, Shin HR. Awareness of and attitude towards human papillomavirus infection and vaccination for cervical cancer prevention among adult males and females in Korea: a nationwide interview survey. Vaccine. 2010;28(7):1854-60. doi:10.1016/j.vaccine.2009.11 079. Epub 2009 Dec 14.

28. Xu C, Zhang W, Wu M, Zhang S. Knowledge of cervical cancer among 25-54-year-old women in Beijing. J Cancer Educ. 2011;26(3):555-9. doi:10.1007/s13187-011-0228-9.

29. Mary B, D'Sa JL. Evaluation of an educational program on cervical cancer for rural women in Mangalore, Southern India. Asian Pac J Cancer Prev. 2014;15 (16):6603-8.

30. Rahangdale L. Pap tests every 3-5 years: what happens to the annual examination? Obstet Gynecol. 2012;120(1):9-11. doi:10.1097/AOG.0b013e $31825 \mathrm{bd} 729$.

31. Simayi D, Yang L, Li F, Wang YH, Amanguli A, Zhang W, et al. Implementing a cervical cancer awareness program in low-income settings in Western China: a community-based locally affordable intervention for risk reduction. Asian Pac J Cancer Prev. 2013;14(12):7459-66.

32. Basu P, Hassan S, Fileeshia F, Mohamed S, Nahoodha A, Shiuna A, et al. Knowledge, attitude and practices of women in Maldives related to the risk factors, prevention and early detection of cervical cancer. Asian Pac J Cancer Prev. 2014;15(16):6691-5.

33. Pan XF, Zhao ZM, Sun J, Chen F, Wen QL, Liu K, et al. Acceptability and correlates of primary and secondary prevention of cervical cancer among medical students in southwest China: implications for cancer education. PLoS One. 2014;9(10):e110353. doi 10.1371/journal.pone.0110353. eCollection 2014.

34. Montgomery MP, Dune T, Shetty PK, Shetty AK. Knowledge and acceptability of human papillomavirus vaccination and cervical cancer screening among women in Karnataka. India J Cancer Educ. 2014;30(1):130-7.

\section{Submit your next manuscript to BioMed Central and take full advantage of:}

- Convenient online submission

- Thorough peer review

- No space constraints or color figure charges

- Immediate publication on acceptance

- Inclusion in PubMed, CAS, Scopus and Google Scholar

- Research which is freely available for redistribution 